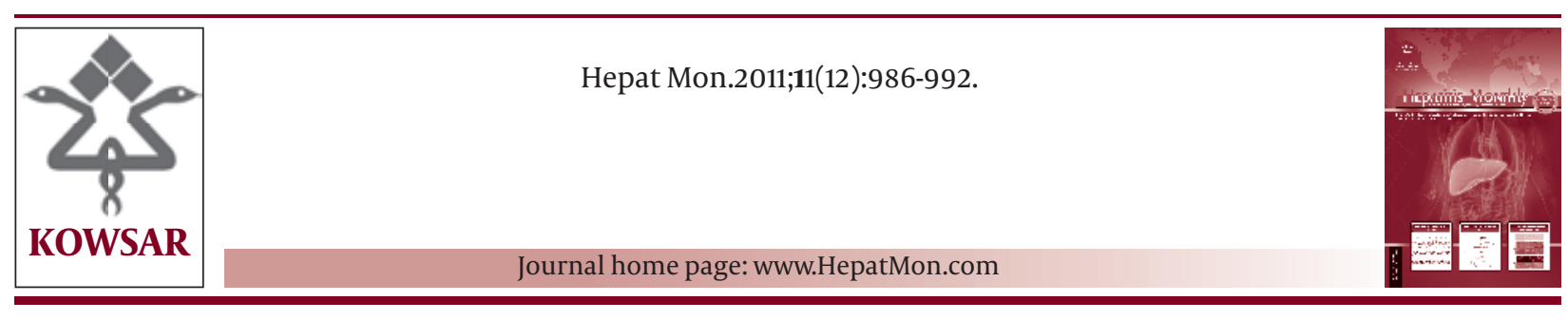

\title{
Intravenous Drug Users Can Achieve a High Sustained Virological Response Rate: Experience From Croatian Reference Center for Viral Hepatitis
}

\author{
Ivan Kurelac ${ }^{1}$, Neven Papic ${ }^{1 *}$, Slavko Sakoman ${ }^{2}$, Mirjana Orban ${ }^{2}$, Davorka Dusek ${ }^{1}$, Marijana \\ Coric $^{3}$, Adriana Vince ${ }^{1}$ \\ ${ }^{1}$ Croatian Reference Center for Viral Hepatitis, University Hospital for Infectious Diseases, Zagreb, Croatia \\ 2 Department of Psychiatry, Ward of Addictions, Sisters of Mercy University Hospital, Zagreb, Croatia \\ ${ }^{3}$ Department of Pathology, Clinical Hospital Centre Zagreb, Zagreb, Croatia
}

\begin{tabular}{l}
\hline A R T I C L E I N F O \\
\hline Article type: \\
Original Article \\
\hline Article history: \\
Received: 06 Aug 2011 \\
Revised: 02 Sep 2011 \\
Accepted: 29 Sep 2011 \\
\hline
\end{tabular}

Keywords:

Behavior, Addictive

Injections

Infusions, Intravenous

Hepatitis, Chronic

Hepatitis C

\begin{abstract}
A B S T R A C T
Background: Hepatitis C virus (HCV) is one of the major infectious disease agents among injecting drug users (IVDUs). However, most of the IVDUs are not still treated.

Objectives: To examine the treatment course, adherence, tolerability and safety profiles and SVR rates in IVDUs compared to non-IVDUs.

Patients and Methods: Demographic and clinical data were collected from medical records of 345 adult patients diagnosed with chronic hepatitis C (CHC) who were treated with a PEG-IFN- $\alpha$ and ribavirin in Croatian Reference Center for Viral Hepatitis in Zagreb between January 2003 and January 2010. Efficacy, safety and tolerability treatment profiles were analyzed in IVDUs vs. non-IVDUs. Positive predictors for treatment outcome were evaluated by univariate and multivariate logistic regression.

Results: A total of 106 (30.46\%) IVDUs were identified. The IVDUs were mainly male ( $81.13 \%$ vs. $52.30 \%, P=0.0001$ ), young (mean \pm SD age: $32.46 \pm 5.33$ y vs. $46.12 \pm 11.48 \mathrm{y}, P=0.0001$ ), had lower fibrosis and HAI score (measured by ISHAK) and shorter duration of infection (mean \pm SD: $8.98 \pm 5.87 v$ s. $16.79 \pm 8.99 \mathrm{y}, P=0.0001$ ) compared to non-IVDU group. In IVDUs, genotype 1a $(24.52 \%)$ and $3 a(38.68 \%)$ were predominant. There were no differences in completion rate between the two studied groups. IVDUs achieved a significantly higher rate of overall SVR $(70.75 \% v s .51 .04 \%, P<0.0009)$ and in genotypes 1 and $4(65.08 \%$ vs. $48.73 \%, P=0.0294)$ vs. non-IVDUs. Treatment discontinuation rates due to side-effects were not significantly different in IVDUs and non-IVDUs $(2.83 \% v s .7 .11 \%, P=0.1390)$. IVDU group had a higher rate of lost to follow-up (13.21\% vs. $4.60 \%, P=0.0071)$. There were no statistically significant differences in SVR rate between IVDUs with, or without substitution therapy (55.55\% vs. 74.62\%, $P=0.0866)$. Independent predictors of SVR were age $<40$ years and genotypes 2 and 3. Type of PEG-IFN- $\alpha$ used was not associated with SVR.

Conclusions: Treatment of CHC in IVDUs should strongly be encouraged as they have positive predictors for achieving SVR such as younger age, shorter duration of infection, and consequently favorable histological stage of the disease, and good adherence to treatment. There is no difference in safety and tolerability profiles of treatment in IVDUs compared to patients with no history of drug abuse.
\end{abstract}

Copyright $\odot 2011$ Kowsar M. P. Co. All rights reserved.

- Implication for health policy/practice/research/medical education:

This study evaluate the prevalence of hepatitis $\mathrm{C}$ among injecting drug users. We highly recommended the gastroenterologists and virologists to study this article.

\footnotetext{
${ }^{*}$ Corresponding author: Neven Papic, Department of Viral Hepatitis, University Hospital for Infectious Diseases, Mirogojska 8, 10000 Zagreb, Croatia.Tel:+385-12826262, Fax:+385-14678235, E-mail: npapic@bfm.hr
} 
Please cite this paper as:

Kurelac I, Papic N, Sakoman S, Orban M, Dusek D, Coric M, et al. Intravenous Drug Users Can Achieve a High Sustained Virological Response Rate: Experience From Croatian Reference Center for Viral Hepatitis. Hepat Mon. 2011;11(12):986-992.

\section{Background}

The disordered life-style of many intravenous drug users (IVDUs) represents a serious health risk and is strongly associated with social disadvantages. Sharing equipment for drug injection is the most important factor for blood-borne infection transmission (1). IVDU is associated with high risk for transmission of human immunodeficiency virus (HIV) and hepatitis B (HBV) and C (HCV). $\mathrm{HCV}$ is far more infectious than HIV in terms of bloodborne transmission, and shows much higher seroprevalence rates among IVDUs (1-3). Studies show that 60\%-90\% of patients with intravenous drug abuse are chronically infected with HCV. Incoming data reveals a prevalence of HCV among new IVDUs (injecting less than two years) of $40 \%$, making this problem a global public health priority (4-6). Currently available standard-of-care, pegylated interferon-alpha (PEG-IFN- $\alpha$ ) and ribavirin (RBV) therapy, successfully eradicates HCV infection in up to $55 \%$ of patients, as measured by sustained virological response (SVR) $(7,8)$. However, this treatment has numerous side effects, among which neuropsychiatric disorders play an important role in keeping adherence to the therapy $(7,8)$.

Previous treatment guidelines and recommendations for the management of chronic hepatitis $\mathrm{C}(\mathrm{CHC})$ discouraged treatment of HCV in IVDUs (9), but even after the guidelines have been liberalized over the past ten years, most of IVUDs are still not treated (10). Concerns about the abstinence, risk of reinfection, concomitant substitution therapy and alcohol abuse, and low treatment compliance, are the main reasons for treatment denial $(10,11)$. Only one-third of the infected former IVDUs receive antiviral treatment $(10,12)$. However, recently published studies contradict this prejudice by showing that IVDUs can be treated effectively and safely, especially those on methadone maintenance or similar opiate substitution therapy (13-15). Moreover, treatment of IVDUs becomes imperative for every efficient public health program. There can be no decrease in HCV prevalence in general population without management of infection in IVDUs. The reported prevalence rate of IVDU in European Union is estimated to be between 3.6 and 4.4 cases per 1000 (in population aged 15-64 years), and the general decreasing trend has been noticed over the past ten years (4). Reports from Croatia show similar prevalence and stable epidemiological situation. Similar to some other European countries, Croatia has high HCV prevalence among IVDUs $(4,16-18)$. Kolaric, et al., reported the seroprevalence of anti-HCV up to $65 \%$, among imprisoned IVDUs in the three largest Croatian cities, representing a significant burden to Croatian health care system (16).

\section{Objectives}

This study was conducted to examine the treatment course, safety and tolerability profile, adherence to treatment and rates of SVR in IVDUs compared to non-IVDUs with CHC, treated at the Croatian Reference Center for Viral Hepatitis, the largest center for HCV-positive patients in Croatia.

\section{Patients and Methods}

A retrospective study including 345 adult patients, 211 men $(61.16 \%)$ and 134 women (38.84\%), with a mean \pm SD age of $41.92 \pm 11.82$ years, was conducted at the Croatian Reference Center for Viral Hepatitis, Zagreb, Croatia. A total of 106 IVDUs were recognized in the group, representing $30.46 \%$ of those treated. A history of blood transfusion was a clear risk factor for HCV in 112 (32.46\%) patients. A history of having been stuck with a bloody needle or sharp instrument (not IVDU-associated) was reported in 49 (14.2\%) patients, sexual-behavior risk factors in $7(2.03 \%)$ patients and the risk associated with tattooing was reported in 1 (0.31\%) patient. In 70 (20.28\%) patients risk factor remained unknown.

Two-hundred and one (58.26\%) patients were treated with Peg-IFN- $\alpha 2 a 180 \mu \mathrm{g} /$ week + RBV; 144 (41.74\%) were treated with Peg-IFN- $\alpha 2$ b $1.5 \mu \mathrm{g} /$ week + RBV. RBV was administered at the recommended dosage. The duration of therapy in genotypes 1 and 4 was 48 weeks, and in genotypes 2 and 3 was 24 weeks. Therapy was discontinued in $\mathrm{HCV}$ genotype 1 and $\mathrm{HCV}$ genotype 4 patients if viral load decreased by less than 2 log HCV RNA copies/mL at week 12 compared with baseline values or if HCV RNA was still detectable at week 24 . In this study, we compared the age, gender, genotype, stage of fibrosis, type of PEG-IFN- $\alpha$, treatment safety profile and the sustained virological response (SVR) rates among IVDUs and patients with no history of drug use. The second objective of this study was to assess the influence of substitution therapy on achieving SVR in the group of IVDUs.

\subsection{Definitions}

SVR was defined as undetectable HCV RNA 24 weeks after therapy with combined PEG-IFN $\alpha-2 a$ or $\alpha-2 b$ plus RBV. HCV RNA quantification was performed by using COBAS Ampliprep/COBAS TaqMan HCV test (Roche diagnostics, diagnostic systems Pleasanton, CA). HCV genotyping was performed by using VERSANT HCV Genotyping assay (LIPA) (Bayer diagnostics, Puteaux, Cedex, France) at the Department of Molecular Diagnostics and Cellular Immunity, UHID. Liver biopsy was performed at the De- 
partment of Viral Hepatitis, UHID and the ISHAK scoring system was used to assess the histological activity (19). Disease duration was estimated by considering the date of blood transfusion received prior to 1993, the date of surgery, or the period of drug injection as the onset of infection. All the IVDUs treated at UHID were abstinent for at least six months, so the active drug users were not enrolled in our study.

\subsection{Data Collection}

Patient records of all patients that started treatment at UHID between January 2003 and January 2010 were extracted and used for collection of clinical and laboratory data. Ethics Committee of UHID approved this study. Virologic results and liver biopsy data were doublechecked at the available databases of the Department of Molecular Diagnostic and Cellular Immunity, UHID, and Department for Viral Hepatitis, UHID.

\subsection{Statistical Analysis}

Statistical analyses were performed using Prism (ver 5.0) statistical software (GraphPad Software, San Diego, CA) and MedCalc for Windows ${ }^{\circledR}$, ver 11.5.1.0 (MedCalc Software, Mariakerke, Belgium). The demographic, clinical characteristics and laboratory data were evaluated and presented descriptively. $\chi^{2}$, Fisher's exact test and Mann Whitney U test were used to compare the groups, as appropriate. All tests were two-tailed; a $P<0.05$ was considered statistically significant. Binary logistic regression analysis was used to assess the independent predictors of SVR. The strength of association was expressed as odds ratio (OR) and its corresponding 95\% confidence interval (CI). The unadjusted univariate OR was also calculated for every predictor. All predictors were entered in a backward stepwise logistic regression model with SVR being the dependent variable. The initial model included all predictors: antiviral therapy (Peg-IFN- $\alpha 2 a$ vs. Peg-IFN$\alpha 2 b)$, age ( $\leq 40$ years $v s .>40$ years), gender, body weight ( $\leq 75 \mathrm{~kg} v \mathrm{~s} .>75 \mathrm{~kg}$ ), HCV-genotype (1 and 4 vs. 2 and 3), extent of fibrosis (mild fibrosis: ISHAK 0-2 vs. significant fibrosis: ISHAK 3-6), presence of risk factor (IVDU $v$ s. nonIVDU), and duration of infection. Statistically non-significant predictors were progressively excluded based on a likelihood ratio test.

\section{Results}

\subsection{Patients Characteristics}

The IVDUs group was predominately young males with lower extent of fibrosis and HAI score (measured by ISHAK) and had typically a shorter duration of infection than non-IVDU group. There were significant differences in genotype distribution between the two groups: The genotype $1 \mathrm{~b}$ was strongly associated with patients without history of drug abuse (transfusion and surgery), while in IVUDs genotypes 1a and 3a were predominant, with 3a being far more frequent than in other populations. The mean \pm SD duration of IVDU abstinence was $4.76 \pm 3.16$ (range: $0.5-18$ ) years. The distribution of selected variables is presented in Table 1.

\begin{tabular}{|c|c|c|c|}
\hline & $\begin{array}{l}\text { Intravenous Drug Users } \\
(\mathbf{n}=\mathbf{1 0 6})\end{array}$ & $\begin{array}{l}\text { No History of Drug Abuse } \\
(n=239)\end{array}$ & $P$ value \\
\hline \multicolumn{4}{|l|}{ Demographic characteristics, No. (\%) } \\
\hline Male & $86(81.13)$ & $125(52.30)$ & $0.0001^{b}$ \\
\hline Female & $20(18.87)$ & $114(47.70)$ & \\
\hline Age, $y$, mean $\pm S D^{a}$ & $32.46 \pm 5.33$ & $46.12 \pm 11.48$ & $0.0001^{\mathrm{c}}$ \\
\hline Weight, kg, mean \pm SD & $78.94 \pm 15.02$ & $73.57 \pm 14.27$ & $0.0129^{c}$ \\
\hline \multicolumn{4}{|l|}{ Genotype, No. (\%) } \\
\hline Total $^{\mathrm{d}}$ & $59(55.66)$ & $188(78.66)$ & $0.0001^{b}$ \\
\hline Subtype 1a & $26(24.52)$ & $15(6.27)$ & $0.0001^{b}$ \\
\hline Subtype $1 b$ & $20(18.87)$ & $129(53.97)$ & $0.0001^{b}$ \\
\hline Subtype 2 & $2(1.87)$ & $3(1.25)$ & $0.6448^{b}$ \\
\hline Subtype $3 / 3 a$ & $41(38.68)$ & $39(16.32)$ & $0.0001^{b}$ \\
\hline Subtype 4 & $4(3.79)$ & $9(3.77)$ & $0.5034^{b}$ \\
\hline \multicolumn{4}{|l|}{ Liver biopsy (ISHAK score) $(\mathrm{n}=262,81+181)$} \\
\hline Fibrosis; median $\left(\mathrm{IQR}^{\mathrm{a}}\right)$ & $3(3-3)$ & $3(3-4)$ & $0.004^{c}$ \\
\hline Histology activity score; median (IQR) & $7(6-9)$ & $8(6-11)$ & $0.008^{c}$ \\
\hline Duration of infection, $y$, mean \pm SD & $8.98 \pm 5.87$ & $16.79 \pm 8.99$ & $0.001^{\mathrm{c}}$ \\
\hline \multicolumn{4}{|l|}{ Therapy, No. (\%) (n=189, 83+106) } \\
\hline PEG-IFN- $\alpha 2 \mathrm{a}^{\mathrm{a}}$ & $67(63.20)$ & $134(56.07)$ & $0.1917^{b}$ \\
\hline PEG-IFN- $\alpha 2 b$ & $39(36.80)$ & $105(43.93)$ & \\
\hline
\end{tabular}




\begin{tabular}{lll}
\hline Table 2. Reported Side-Effects During PEG-IFN- $\alpha$ Therapy & & \\
\hline Anemia & $\begin{array}{l}\text { Intravenous Drug Users, No. (\%) } \\
(\mathbf{n}=\mathbf{1 0 6})\end{array}$ & $\begin{array}{l}\text { No History of Drug Abuse, No. (\%) } \\
(\mathbf{n}=\mathbf{2 3 9})\end{array}$ \\
Neutropenia & $19(17.92)$ & $45(18.82)$ \\
Thrombocytopenia & $7(6.66)$ & $26(10.87)$ \\
Atralgiae/mialgiae & $5(4.71)$ & $19(7.94)$ \\
Dermatological (including dermatitis, rash, pruritus) & $26(24.52)$ & $21(8.78)$ \\
Hipo/hiperthyreosis & $8(7.54)$ & $68(28.45)$ \\
Flu-like symptoms & $3(2.83)$ & $6(2.51)$ \\
Respiratory symptoms & $49(46.23)$ & $108(45.18)$ \\
Anxiety & $2(1.88)$ & $3(1.25)$ \\
Depression & $21(19.81)$ & $35(14.64)$ \\
Insomnia & $9(8.49)$ & $6(2.51)$ \\
Headache & $8(7.54)$ & $6(2.51)$ \\
\hline
\end{tabular}

\subsection{Treatment Safety, Modifications and Discontinua- tion}

The safety and tolerability profiles of treatment were compared in IVDU and non-IVDU groups. Both groups had similar frequencies of side-effects (despite the different response rates described below). Among IVDU patients, 75 (70.75\%) reported at least one side-effect, but only 12 of them (11.32\%) required dose reduction and 3 (2.83\%) needed therapy discontinuation. Sixteen (15.09\%) patients reported only one side-effect, 35 (33.33\%) two, and 24 (22.64\%) three or more side-effects. Among patients with no history of drug abuse, $178(74.47 \%)$ reported sideeffects, $38(15.89 \%)$ required dose reduction and $17(7.11 \%)$ needed therapy discontinuation. Twenty-six (10.87\%) patients reported one, 64 (26.78\%) two and 88 (36.82\%) three or more side-effects. The frequency of most common side-effects is shown in Table 2. Next, we analyzed possible safety differences IVDU patients treated with two different PEG-IFN- $\alpha$ regiments. Regarding psychiatric side-effects, it was recorded that anxiety, depression and insomnia were more frequent in IVDU group, although it did not reach a statistically significant level (Table 2)

Psychiatric side-effects were more frequent in patients treated with PEG-IFN-a2a, but there were no statistically significant differences in general and psychiatric sideeffects. Among IVDUs treated with PEG-IFN-2 $\alpha, 14$ (20.89\%) patients reported anxiety problems, 6 (8.95\%) insomnia and $8(11.94 \%)$ depression. In IVDUs treated with PEG-IFN$2 \alpha \mathrm{b}, 7(17.94 \%)$ reported anxiety problems, 2 (5.13\%) insomnia and one depression (2.56\%). Moreover, correlation analysis did not reveal any association between the type of PEG-IFN administered and therapy modification or discontinuation $(\mathrm{OR}=1.87$; 95\% CI: $0.74-4.42 ; P=0.1441)$. However, the influence of relatively small sample of patients within analyzed variables cannot be excluded.

Analysis of the reduction of therapy was evaluated in all 345 patients (Table 3). There were no statistically significant differences in reduction and discontinuation rates between the two groups. The reasons for treatment dis- continuation in IVDU group were severe anemia, neutropenia and severe depression that did not improve after dose reduction and supportive therapy.

\subsection{Virological Response}

Analysis included data from all patients who received at least one dose of medication (intention-to-treat analysis). In the whole group, SVR was achieved in 197 (57.10\%) of 345 patients, SVR rate for genotypes 1 and 4 was $52.69 \%$ and for genotypes 2 and 3 was $74.11 \%$ (Table 3).

To determine influence of previous intravenous drug use on achieving SVR, IVDUs and non-IVDUs groups were compared. Overall, IVDUs group had a higher SVR rate (70.75\% vs. 51.04\%, $P=0.0009$ ), particularly in those with genotypes 1 and $4(65.08 \% v s .48 .73 \%, P=0.0294$, Fisher's exact test) when compared to non-IVDU group. Although the SVR rate was better in IVDU patients with genotypes 2 and 3 than in non-IVDU patients, the difference was not statistically significant. Additionally, IVDU group had a higher rate of lost to follow-up (13.21\% vs. 4.60\%, $P$ $=0.0071$ ), i.e. $13 \%$ of IVDUs did not come for final evaluation 24 weeks after therapy. There was no statistically significant difference in SVR rates between patients treated with PEG-IFN- $\alpha 2 a$ and PEG-IFN- $\alpha 2 b$.

\subsection{Influence of Substitution Therapy With Methadone/ Buprenorphine on Adherence and SVR}

Data for substitution therapy were available for 94 (88.68\%) of 106 patients. There were no complete medical records for 12 patients. According to records, 12 (12.76\%) patients were on methadone-maintained therapy, 15 (15.96\%) were on buprenorphine, and 67 (71.28\%) received no substitution therapy. Duration of abstinence was shorter in patients receiving maintenance therapy (mean \pm SD: $3.61 \pm 2.33 v s .5 .41 \pm 3.26 \mathrm{y}, P=0.0170$ ). To determine the influence of substitution therapy on treatment course, SVR and lost to follow-up rates, were compared in IVDUs receiving substitution therapy and those who did not receive substitution therapy. The treatment 


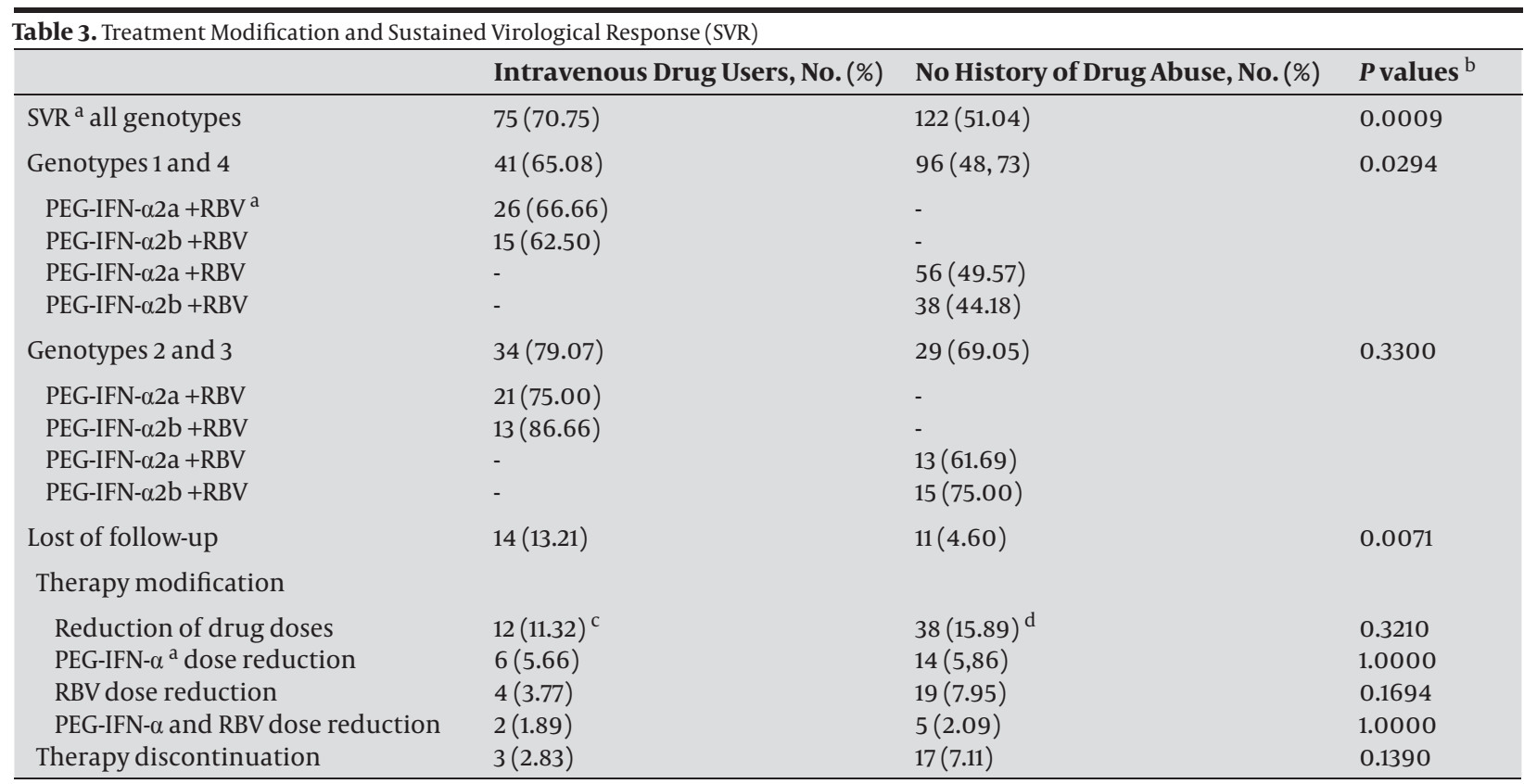

${ }^{a}$ Abbreviations: PEG-IFN- $\alpha$, pegylated-interferon alpha; RBV, ribavirin; SVR, sustained virological response

b Fisher's exact test

${ }^{\mathrm{c}}$ Reasons for treatment modification in IVDUs: anemia 4, neutropenia 3, hypothyroidism 2, depression 2, pancytopenia 1

${ }^{\mathrm{d}}$ Reasons for treatment modification: anemia 14, neutropenia 8, thrombocytopenia 7, depression 5, hypothyroidism 4

\begin{tabular}{llll}
\hline Table 4. Influence of Substitution Therapy on the Level of Adherence to Treatment & & \\
\hline & $\begin{array}{l}\text { Methadone/Buprenorphine Therapy } \\
(\mathbf{n}=\mathbf{2 7})\end{array}$ & $\begin{array}{l}\text { No Substitution Therapy } \\
(\mathbf{n}=\mathbf{6 7})\end{array}$ & P value $^{\text {b }}$ \\
\hline SVR (ITT analysis & a), No. (\%) & $50(74.62)$ & 0.0866 \\
SVR genotype 1 and 4 & $15(55.55)$ & $32(72.72)$ & 0.0442 \\
SVR genotype 2 and 3 & $5(38.46)$ & $18(78.26)$ & 0.7046 \\
Lost of follow-up, No. (\%) & $10(71.42)$ & $7(10.44)$ & 0.1050 \\
Treatment completion rate, No. (\%) & $7(25,92)$ & $64(95.52)^{\mathrm{c}}$ & 0.5546 \\
\hline
\end{tabular}

a Abbreviation: ITT, intention-to-treat analysis

${ }^{\mathrm{b}}$ Fisher's exact test

${ }^{\mathrm{c}}$ In three patients treatment was discontinued

completion rate was better in the former group. However, patients on substitution therapy had lower SVR rates measured by intention-to-treat analysis, mainly because of a higher rate of lost to follow-up found in those who received substitution therapy (Table 4).

\subsection{Predictors of SVR}

Univariate and multivariate binary logistic regression analyses were performed to identify independent predictors of SVR (Table 5). Univariate analysis revealed five significant associations: Patients' age ( $<40$ years), genotypes 2 and 3, extent of liver fibrosis (mild fibrosis: ISHAK 1-2), duration of infection and risk factor IVDU. Patients' weight and type of PEG-IFN- $\alpha$ were not associated with SVR in our model. However, using a multivariate logistic regression model (stepwise backward method) we came out to two indepent predictors of SVR-patients' age $<40$ years and genotypes 2 and 3 . The area under the receiver-operating-characteristic curve in the fully adjusted binary logistic regression model (with the selected predictors) was 0.718 , which indicates a good discriminatory accuracy.

\section{Discussion}

According to the World Health Organization, the estimated prevalence of HCV infection in general population in Croatia is $1.4 \%$, while in IVDUs it is up to $69 \%(16,18$, 20). IVDUs represent significant part of the population treated at Croatian Reference Center for Viral Hepatitis, as $30.46 \%$ of treated patients in study period were previous IVDUs. Many patients with $\mathrm{CHC}$ who are active or past IVDUs are still excluded from treatment programs. However, results from our study confirm previously published data which shows that IVDUs can be treated effectively and safely $(13,15,21)$. Also, our study showed that IVDUs have even higher SVR rates, most likely because they have positive predictors for achieving SVR such as younger age, shorter duration of infection, and lower fi- 


\begin{tabular}{|c|c|c|c|c|}
\hline & \multicolumn{2}{|c|}{ Univariate Analysis } & \multicolumn{2}{|c|}{ Multivariate Analysis $^{\mathrm{b}}$} \\
\hline & Crude Odds-Ratio $\left(95 \% \mathrm{CI}^{\mathrm{a}}\right)$ & $P$ value & Adjusted Odds-Ratio (95\% CI) & Pvalue \\
\hline Patients ${ }^{\mathrm{c}}$ & $2.15(0.97-4.78)$ & $<0.0001$ & $2.98(1.50-5.84)$ & 0.0017 \\
\hline Genotype 2 and 3 & $17.36(4.09-73.62)$ & $<0.0001$ & $25.40(3.44-194.82)$ & 0.0016 \\
\hline Mild fibrosis (ISHAK score $0,1,2$ ) & $1.87(0.79-4.42)$ & 0.0149 & - & - \\
\hline Duration of infection & $0.96(0.93-0.99)$ & 0.0265 & - & - \\
\hline Intravenous drug use (risk factor) & $3.38(1.17-9.73)$ & 0.0236 & - & - \\
\hline
\end{tabular}

a Abbreviation: $\mathrm{CI}$, confidence interval

${ }^{\mathrm{b}}$ Complete data for 172 patients

${ }^{\mathrm{c}}$ Age $<40 \mathrm{y}$

brosis score.

Currently, in Western Europe and the USA the genotype $1 \mathrm{~b}$ is strongly associated with transfusion-related HCV infection, while HCV in IVUDs is mainly associated with genotypes 1a and 3a $(4,22,23)$. Genotype distribution among IVDUs in our study follows the previously reported pattern. Additionally, the genotype distribution in this study in comparison with previously published data from our center shows an increasing trend in frequency of genotypes $1 \mathrm{a}$ and $1 \mathrm{~b}$ in IVDUs (24). Similarly, authors from France reported a significant increase in prevalence of genotypes 1a and 3a in IVDUs during the last three decades (25).

One of the main concerns when treating IVDUs is their adherence to treatment. The reported completion rate among IVDUs is around 70\%, with significant differences among countries and medical centers (12). Treatment completion rate in our study was $97.17 \%$ in IVDUs, and $92.89 \%$ in non-IVDU group. Additionally, treatment completion rate was better in patients receiving substitution therapy than in those who did not, although we noticed a higher rate of patients who were lost to follow-up in patients who received substitution therapy. Patients were closely monitored during the treatment and coming for regular controls every four weeks in our center, and if they experienced any new side-effects they could contact us at any time. Additional follow-up was provided by psychiatrist at centers for treatment of addiction. This could explain the very good adherence rate observed in IVDUs which was even higher than non-IVDU group. It has been shown that substitution therapy effectively reduces the opiate need, HIV risk behaviors and transmission, general mortality and criminal behavior $(26,27)$. Methadone maintenance treatment (MMT) programs, which require regular contact with patients, presumably promote adherence to antiviral treatment. There are several studies that promote positive effects of MMT therapy and show that comprehensive, on site model of drug abuse treatment with CHC management has improved the SVR rate $(14,21,26,27)$. Meanwhile, IVDUs treated at specialized liver clinics without integral care model reported lower adherence and SVR rates $(11,12,15)$.

Results from a recently published meta-analysis have shown that tolerability of CHC treatment in IVDUs is comparable to that of general population, with rate of psychiatric side-effects being $2 \%$ (15). Our study also showed that treatment with PEG-INF- $\alpha$ and RBV is safe in IVDUs, but with close psychiatric monitoring. Safety and tolerability profiles in IVDU and non-IVDU group were similar, with psychiatric side-effects (anxiety, depression and insomnia) were more frequent in IVDU group, although not at a statistically significant level. An interesting point of our study is that, although there was no statistically significant difference in treatment modification or discontinuation between two studied groups, a higher trend toward discontinuation was noticed in non-IVDU group than in IVDU group (7.11\% vs. $2.83 \%, P=$ 0.139 ). In an Italian study discontinuation rate due to severe depression was $3.8 \%$; in our study only $1.8 \%$ of IVDUs had to discontinue treatment for severe depression (14). Recent studies suggested that IVDUs treated with PEGIFN- $\alpha$ and RBV can achieve an SVR rate equivalent to that obtained in registration trials, with SVR rates ranging from $39 \%$ to $61 \%(12,15,28)$. Differences in SVR rates could be explained by different study design and inclusion of active IVDUs. In our study, SVR rate for IVDUs was $65.1 \%$ for genotypes 1 and 4 , and $79.1 \%$ for genotypes 2 and 3, which was higher than that in non-IVDU group (48.7\% and $69.1 \%$, respectively). Results of this study were somewhat similar to the study of Manolakopoulos, et al, where SVR rates were also higher than those in registration trials, with an SVR rate for genotypes 1 and 4 being 57.6\%, and for genotypes 2 and 3 was 78.3\%. Higher SVR rates in IVDU group can be explained by significantly higher proportion of patients who were young, had shorter duration of infection, lower fibrosis score and higher percentage of genotypes 2 and 3 (21). The limitations of this study included its retrospective nature, collection of data from a single institution, and a modest sample size. Although we present data from a single institution, our hospital is the Croatian Reference Center for Viral Hepatitis, where the majority of patients from all Croatia are treated. It was beyond the scope of this study to review every chart to determine what percentage of all IVDUs patients with $\mathrm{CHC}$ were evaluated for and offered HCV treatment. Interestingly, the patients with longer abstinence period and who did not receive substitution therapy usually came to seek the treatment on their own decision, while patients 
receiving substitution therapy were recommended for the treatment by their psychiatrists. Our data clearly suggest that adherence of IVDUs was excellent which resulted in a high SVR rate. Treatment of CHC in IVDUs should strongly be encouraged as they present a group with favorable predictors for achieving SVR. Timing for therapy for patients with substitution therapy and adherence, as well as treatment of side effects, should be considered as an important goal of multidisciplinary approach. On the other hand, the awareness of successful treatment of HCV infection can be an important "turning" point in reducing or stopping the substance abuse.

\section{Acknowledgments}

None declared.

\section{Financial Disclosure}

None declared.

\section{Funding/Support}

This study was partly supported by a grant from the Croatian Ministry of Science, Education and Sports to Prof. A. Vince (143-0000000-0117). The funders had no role in the study design, data collection and analysis, decision to publish, or preparation of the manuscript.

\section{References}

1. Paintsil E, He H, Peters C, Lindenbach BD, Heimer R. Survival of hepatitis $C$ virus in syringes: implication for transmission among injection drug users. J Infect Dis. 2010;202(7):984-90.

2. Mehta SH, Astemborski J, Kirk GD, Strathdee SA, Nelson KE, Vlahov D, et al. Changes in blood-borne infection risk among injection drug users. J Infect Dis. 2011;203(5):587-94.

3. Gordon SC, Elloway RS, Long JC, Dmuchowski CF. The pathology of hepatitis $C$ as a function of mode of transmission: blood transfusion vs. intravenous drug use. Hepatology. 1993;18(6):1338-43.

4. European Monitoring Centre for Drugs and Drug Addiction (EMCDDA). 2010 Annual report on the state of the drugs problem in Europe. Lisbon; 2010; Available from: http://www.emcdda.europa.eu/publications/annual-report/2010.

5. Mathei C, Buntinx F, van Damme P. Seroprevalence of hepatitis C markers among intravenous drug users in western European countries: a systematic review. J Viral Hepat. 2002;9(3):157-73.

6. Reimer J, Lorenzen J, Baetz B, Fischer B, Rehm J, Haasen C, et al. Multiple viral hepatitis in injection drug users and associated risk factors. J Gastroenterol Hepatol. 2007;22(1):80-5.

7. McHutchison JG, Lawitz EJ, Shiffman ML, Muir AJ, Galler GW, McCone $\mathrm{J}$, et al. Peginterferon alfa-2b or alfa-2a with ribavirin for treatment of hepatitis C infection. NEngl JMed.2009;361(6):580-93.

8. Rumi MG, Aghemo A, Prati GM, D'Ambrosio R, Donato MF, Soffredini R, et al. Randomized study of peginterferon-alpha2a plus ribavirin vs peginterferon-alpha2b plus ribavirin in chronic hepatitis C. Gastroenterology. 2010;138(1):108-15.

9. National Institutes of Health Consensus Development Conference Panel statement: management of hepatitis C. Hepatology. 1997;26(3 Suppl 1):2S-10S.

10. Gazdag G, Horvath G, Szabo O, Ungvari GS. Barriers to antiviral treatment in hepatitis $\mathrm{C}$ infected intravenous drug users. Neuropsychopharmacol Hung. 2010;12(4):459-62.

11. Grebely J, Petoumenos K, Matthews GV, Haber P, Marks P, Lloyd $\mathrm{AR}$, et al. Factors associated with uptake of treatment for recent hepatitis $C$ virus infection in a predominantly injecting drug user cohort: The ATAHC Study. Drug Alcohol Depend. 2010;107(23):244-9.

12. Hellard M, Sacks-Davis R, Gold J. Hepatitis C treatment for injection drug users: a review of the available evidence. Clin Infect Dis. 2009;49(4):561-73.

13. Schaefer M, Mauss S. Hepatitis C treatment in patients with drug addiction: clinical management of interferon-alpha-associated psychiatric side effects. Curr Drug Abuse Rev. 2008;1(2):177-87.

14. Belfiori B, Ciliegi P, Chiodera A, Bacosi D, Tosti A, Baldelli F, et al Peginterferon plus Ribavirin for chronic hepatitis $C$ in opiate addicts on methadone/buprenorphine maintenance therapy. Dig Liver Dis. 2009;41(4):303-7.

15. Zanini B, Covolo L, Donato F, Lanzini A. Effectiveness and tolerability of combination treatment of chronic hepatitis $C$ in illicit drug users: meta-analysis of prospective studies. Clin Ther. 2010;32(13):2139-59.

16. Kolaric B, Stajduhar D, Gajnik D, Rukavina T, Wiessing L. Seroprevalence of blood-borne infections and population sizes estimates in a population of injecting drug users in Croatia. Cent Eur J Public Health. 2010;18(2):104-9.

17. Medic A, Dzelalija B, Sonicki Z, Zekanovic D. Characteristics of hepatitis $C$ infection in injecting drug users in Zadar County, Croatia. Coll Antropol. 2008;32(3):697-702.

18. Sakoman S. [Prevention and treatment of hepatitis $C$ in illicit drug users]. Acta Med Croatica. 2009;63(5):437-42.

19. Ishak K, Baptista A, Bianchi L, Callea F, De Groote J, Gudat F, et al. Histological grading and staging of chronic hepatitis.J Hepatol. 1995;22(6):696-9.

20. World Health Organiation. Hepatitis C. Fact sheet $N^{\circ} 164$. Geneva: WHO; 1999 [updated 2011 June]; Available from: http://www.who. int/entity/mediacentre/factsheets/fs164/en/.

21. Manolakopoulos S, Deutsch MJ, Anagnostou O, Karatapanis S, Tiniakou E, Papatheodoridis GV, et al. Substitution treatment or active intravenous drug use should not be contraindications for antiviral treatment in drug users with chronic hepatitis C. Liver Int. 2010;30(10):1454-60.

22. del Olmo JA, Ornia E, Serra MA, Garcia-Torres ML, Escudero A Rodriguez $\mathrm{F}$, et al. Changing prevalence, clinical features, and outcome of acute hepatitis in Spain (1982-2003). J Gastroenterol Hepatol. 2006;21(6):982-7.

23. Wasley A, Alter MJ. Epidemiology of hepatitis C: geographic differences and temporal trends. Semin Liver Dis. 2000;20(1):1-16.

24. Vince A, Iscic-Bes J, Zidovec Lepej S, Baca-Vrakela I, Bradaric N, Kurelac I, et al. Distribution of hepatitis C virus genotypes in Croatia-a 10 year retrospective study of four geographic regions. Coll Antropol. 2006;30(Suppl 2):139-43.

25. Bourliere M, Barberin JM, Rotily M, Guagliardo V, Portal I, Lecomte L, et al. Epidemiological changes in hepatitis $C$ virus genotypes in France: evidence in intravenous drug users.J Viral Hepat. 2002;9(1):62-70.

26. Sylvestre DL, Clements BJ. Adherence to hepatitis C treatment in recovering heroin users maintained on methadone. EurJ Gastroenterol Hepatol. 2007;19(9):741-7.

27. Zaller ND, Bazazi AR, Velazquez L, Rich JD. Attitudes toward methadone among out-of-treatment minority injection drug users: implications for health disparities. Int J Environ Res Public Health. 2009;6(2):787-97.

28. Litwin AH, Harris KA, Jr., Nahvi S, Zamor PJ, Soloway IJ, Tenore PL, et al. Successful treatment of chronic hepatitis $C$ with pegylated interferon in combination with ribavirin in a methadone maintenance treatment program. J Subst Abuse Treat. 2009;37(1):32-40. 